\title{
0 humor corrosivo dos meios e a política: o CQC vai ao Congresso Nacional
}

\section{RESUMO}

O presente artigo é fruto de uma pesquisa que busca analisar o discurso da comunicação em programas de humor de televisão, tendo como objeto de estudo o programa da Rede Bandeirantes Custe o Que Custar, conhecido como CQC. Com o estudo de caso do programa são levantados questionamentos em torno do papel do humor dentro do jornalismo, da construção do discurso do humor na comunicação, de sua relação com a política e dos valores transmitidos. O evento para o qual voltamos nossa atenção foi a suposta expulsão dos repórteres do programa do Congresso Nacional, onde os mesmos faziam uma reportagem. Buscamos, desta forma, discutir as relações entre humor e informação jornalística, desvelando suas vertentes variadas: a leveza, a graça bem como a manipulação e a parcialidade.

\section{PALAVRAS-CHAVE}

humor

comunicação

política

\section{ABSTRACT}

The present article is the result of a research that analyses the communication discourse in humor television programs. Its object is the television show Custe o que custar, through which we seek to raise questions about humor's role within journalism, the construction of humorous discourse in communication and its relationship with politics and the values transmitted as well as the validity of using humor in journalism. The event we analyze more closely is the alleged expulsion of reporters from Brazilian national congress and the repercussions of this action.

\section{KEY WORDS}

humor

communication

politics

\section{Marcio Acselrad \\ Professor da UNIFOR/CE/BR \\ macselrad@gmail.com}

\section{Gabriela Sampaio Dourado}

Graduada em Comunicação Social/jornalismo pela FIC/CE/BR gabidourado@gmail.com
No ano de 2008, um novo programa estréia na grade da televisão aberta: o CQC - Custe o Que Custar, franquia de sucesso em televisões de diversas partes do mundo. Nele jornalismo, política e humor caminham juntos. Apesar disto não ser novidade, o CQC possui uma diferença: aborda os políticos e provoca algumas situações delicadas e por vezes inconvenientes para os parlamentares. Segundo William Davis "o humor pode fazer cair políticos ou pelo menos reduzir-lhes o prestígio pondo-os no ridículo. Também pode evidenciar o caráter hipócrita de certos argumentos".

Na tentativa de obter respostas aos questionamentos populares e cobrar o que havia sido prometido em campanha por alguns políticos, o programa CQC (Custe o Que Custar) vai ao Congresso Nacional e procura entrevistar deputados e senadores que ali se encontram. Fazendo uso do humor, linguagem permitida e explorada no formato adotado pelo programa, o repórter aborda personalidades de renome nacional para lhes perguntar sobre assuntos relacionados à atual situação política do país. Inconveniente e pouco ortodoxo, o repórter termina por ser expulso do Congresso Nacional, o que dá início a uma campanha por parte do programa, que alega ter havido censura à liberdade de imprensa. Neste ponto, $\mathrm{o}$ CQC se apresenta como um programa jornalístico como todos os demais.

A fim de adequar a presente pesquisa às perspectivas acima levantadas, a pesquisa limitou-se a fazer uma análise do discurso desse episódio vivenciado pelo repórter no Congresso Nacional, o qual gerou uma série de discussões sobre o que é jornalismo e o que é humor. $\mathrm{O}$ que se pretende aqui é compreender o papel do humor no jornalismo. As questões que motivaram esta investigação foram: Qual o papel do humor no jornalismo? Como é a construção do discurso do humor na comunicação feita pelo CQC? Que valores são expostos? Que estratégias de manipulação são abordadas? É válido fazer jornalismo desta maneira?

\section{Do humor}

Henri Bergson afirma que o humor dirige-se diretamente à inteligência pura, sendo a emoção sua maior inimiga. Um exercício proposto por Bergson para compreender melhor essa teoria é observar certas situações da vida apenas como espectador: "muitos dramas se transformarão em comédias" (2001, p. 4). Ele chama de "anestesia momentânea do coração" essa indiferença necessária para a produção do efeito da comicidade. $\mathrm{O}$ mesmo se dá quando conseguimos nos distanciar de nossos próprios dramas. Se nos tornamos, mesmo que a custo, espectadores de nossas vidas, nosso próprio dra- 
ma pode se converter em comédia. Muitas vezes isto só é possível com o passar do tempo, donde a conhecida frase "um dia ainda vamos rir disso tudo..."

Outra observação tributada ao filósofo francês é que se trata de um exercício coletivo. Ele não se sustenta sozinho, "parece que o riso precisa de eco" (2001, p. 4).É possível observar em alguns programas humorísticos a presença de um riso artificial, a claque, sempre que alguma piada é contada. Acredita-se que assim se possa estimular o espectador a gargalhar junto. Tal crença parte do princípio que o riso seja fenômeno irrefletido, instintivo, reflexo, com o que não podemos concordar.

Segundo a teoria da superioridade, o humor advém de alguma forma de escárnio. Thomas Hobbes dizia que o riso é um tipo de glória repentina, ligada à sensação de superioridade em relação a alguém. Neste caso, a glória seria um sinônimo de vaidade ou auto-estima. Aqui o riso nasce frente aos acidentes e enfermidades dos outros, às próprias loucuras passadas - desde que haja consciência de tê-las superado - e dos próprios sucessos inesperados. Não são poucas, muito menos recentes, as piadas que provocam o riso a partir de acidentes, defeitos no corpo e minorias sociais. Alexander Bain afirma que todo humor envolve a degradação de algo. Para ele, o objeto de humor não necessariamente precisa ser uma pessoa. Uma instituição política, uma regra social ou qualquer coisa que exija respeito também pode ser ridicularizada.

A análise do Programa Custe o Que Custar, objeto da presente pesquisa, exige bem mais que saber o significado do humor e suas representações. Há que se entender a função deste humor e sua significação no universo da cultura de massa. Exige situar este humor como forte instrumento de manipulação. Forte por ser descomprometido, por não ter a pretensão de ser seguido como uma verdade, por ser descontraído.

É necessário, ainda, entender como e por que o humor pode ser manipulado, usado como uma forma de alienação da sociedade fazendo-a rir de casos sérios que, em verdade, deveriam ser combatidos. Na busca por uma conceituação de ideologia e dominação que mais se aproximasse da proposta desta pesquisa, Thompsom (2002) nos fornece uma resposta coerente quando, paralelamente ao desenvolvimento do conceito de ideologia, elabora também o conceito de dominação. $\mathrm{O}$ sentido ao qual se refere ao falar de dominação é o das "formas simbólicas que estão inseridas nos contextos sociais e circulando no mundo social" (2002, p. 79). As formas simbólicas podem ser ações e falas, imagens e textos com significados produzidos e reconhecidos por sujeitos. Uma forma simbólica pode ser lingüística (um dito ou um texto) ou não-lingüística (uma foto ou uma caricatura).

Estas formas simbólicas auxiliam na construção de um sentido que, quando difundido na vida social, pode ser usado como estratégia para estabelecer e sustentar relações de dominação. Além disso, para que se faça existir, essa dominação necessita vir assentada em um tipo de hierarquia baseada nas relações de poder que emergem de forma sistematicamente assimétrica, ou seja, "quando grupos particulares de agentes possuem poder de uma maneira permanente, e em grau significativo, permanecendo inacessível a outros agentes, ou a grupos de agentes, independentemente da base sobre a qual tal exclusão é levada a efeito" (Thompson, p. 80).

\section{A Sociedade do Espetáculo}

O espetáculo pensado por Debord (1997) transcende a onipresença dos veículos de comunicação de massa, que representam somente o seu aspecto mais visível e mais superficial. É uma forma de sociedade em que a vida real é pobre e fragmentária, e os indivíduos são obrigados a contemplar e a consumir passivamente as imagens de tudo o que lhes falta na existência real.

As imagens que se destacaram de cada aspecto da vida fundem-se num fluxo comum, no qual a unidade dessa mesma vida já não pode ser restabelecida. [...] A especialização das imagens do mundo se realiza no mundo da imagem automizada, em que o mentiroso mente para si mesmo. O espetáculo em geral, como inversão concreta da vida, é o movimento autônomo do não-vivo (Debord, p.13).

De acordo com Jappe (1997), a sociedade do espetáculo exige o olhar para outros (estrelas, homens políticos etc.) que vivem em seu lugar. Nela, a realidade torna-se uma imagem e as imagens tornam-se realidade; a unidade que falta à vida, recupera-se no plano da imagem.

Enquanto a primeira fase do domínio da economia sobre a vida caracterizava-se pela notória degradação do ser em ter, no espetáculo chegou-se ao reinado soberano do aparecer. As relações entre os homens já não são mediadas apenas pelas coisas, como no fetichismo da mercadoria de que Marx falou, mas diretamente pelas imagens (Jappe, 1997).

Neste sentido, e levando às suas conclusões lógicas a teoria da sociedade do espetáculo, não há possibilidade de a própria imagem ser reveladora ou esclarecedora, mantendo-se para sempre na esfera da alienação. O mesmo se pode dizer sobre o humor: mantido refém da lógica espetacular, o humor transforma-se em instrumento apassivador, nunca desvelador ou crítico.

Em Debord, portanto, o desejo audiovisual surge quando o mundo real se transforma em simples imagens, as simples imagens tornam-se seres reais, motivação eficiente e suficiente de um comportamento hipnótico. “O espetáculo, como tendência a fazer ver (por diferentes mediações especializadas) o mundo que já não se pode tocar diretamente, serve-se da visão com o sentido privilegiado da pessoa humana - o que em outras épocas fora o tato" (Debord, 1997, p. 18). A questão da confiabilida- 
de nas imagens aparecerá de forma mais evidente quando analisarmos o caso CQC no Congresso Nacional.

Nunca os profissionais do espetáculo tiveram tanto poder, transcendendo os limites de sua atuação e conquistando domínios que atingem da arte à economia, do viver cotidiano ao fazer política. Tornaram-se senhores da passividade contemporânea. O riso é entretenimento e, para provocá-lo, os programas de televisão buscam diversas maneiras de chamar a atenção do público para que voltem seus olhares para a televisão. Esta espetacularização ocorre no desejo dos programas em obter uma maior audiência e para isso usam de diversos artifícios, dentre os quais se destaca o grotesco, forma de entreter através do riso e também uma maneira de atrair olhares para a televisão.

\section{0 grotesco}

Em meados da década de 60, no Brasil, a televisão já possuía um acervo tecnológico que lhe permitia partir em busca de se consolidar como veículo massivo. Segundo Sodré (2002), já àquela época a televisão se rendia ao comércio e à publicidade numa tentativa de popularização. Assente a isto, a massa se rendia ao conteúdo da televisão buscando diversão e integração no espaço público, ainda que imaginariamente. Com o advento da repressão à liberdade de expressão, fato característico do período da ditadura militar, abria-se espaço para o entretenimento vinculado ao mercado de consumo e à tevê.

Em O Império do Grotesco, Sodré (2002) analisa o conteúdo televisivo como contendo dois padrões de programação: "o 'de qualidade', ou seja, esteticamente clean, bem comportado em termos morais e visuais e sempre fingindo jogar do lado da "cultura"; e o 'do grotesco', em que se desenvolvem as estratégias mais agressivas pela hegemonia da audiência" (Sodré, 2002, p. 130). Nenhum dos dois modelos escapa ao conceito de sociedade do espetáculo, não sendo, portanto, um melhor e outro pior. A estética do grotesco permite grande identificação do espectador com o que é transmitido. Sodré afirma que o grotesco suscita o chamado 'riso cruel', caracterizado como um riso "massivo, pretensamente democrático, em que antigos objetos de indignação (miséria, opressão, falta de solidariedade, descaso dos poderes públicos etc.) recaem na indiferença generalizada." (Sodré, 2002, p.132).

O CQC também tem características do riso grotesco, pois também se utiliza dos problemas alheios para fazer piada. O programa possui um quadro chamado "Proteste Já". Nele, o repórter vai em busca das reclamações de algum grupo social, seja por conta de uma obra inacabada, do barulho da vizinhança ou do transporte público sucateado. Vários tipos de reclamações já foram exibidos no programa.

Ainda que o CQC defenda que a proposta deste quadro é buscar os responsáveis pelos problemas reclamados pela população e tentar resolvê-los, eles fazem pia- da e graça do descaso dos poderes públicos e do sofrimento daquela parcela da população. Rir de alguém que não consegue dormir por conta do barulho de uma obra, de alguém que anda em transporte público sucateado e lotado, que não recebeu um imóvel da maneira que lhe foi garantido quando comprou não deixa de ser uma forma de riso cruel.

\section{Despidos de qualquer personagem quando adentram ao Congresso Nacional, os repórteres querem mostrar que utilizam a ferramenta do humor como base, mas que não são palhaços e que não diferem de outros jornalistas que ali fazem reportagens.}

Sodré também questiona que a impotência humana, política ou social, que para muitos é motivo de risada, vem "compensada" por sorteios e prêmios, financiados pelos patrocinadores comerciais do programa. Por último, afirma que o 'grotesco chocante' é modalidade dominante nas programações para a grande massa na tevê e que permite "encenar o povo e, ao mesmo tempo, mantê-lo à distância" (Sodré, 2002, p.133). O povo vê pessoas ignorantes, patéticas, disformes como uma realidade popular, mas esse choque não chega às causas sociais. Porém, a tevê não é espelho de nenhuma realidade, exceto de si mesma. Tanto a tevê quanto os espectadores encontram-se regidos por um código cultural de mercado.

A história tem mostrado que, à medida que se ampliava a popularização e o sucesso desse tipo de estética na tevê, surgiam cada vez mais programas de conteúdo grotesco. A esse crescimento Sodré chama de "contaminação semiótica [...] pela força catalisadora do marketing num contexto de livre concorrência ou livre circulação da 'moeda' televisiva, em que a facilitação e a banalidade convertem-se em recurso de fácil captação de audiência" (Sodré, 2002, p.138). Um exemplo claro dessa contaminação ocorreu nos anos 90. Com o advento do "medidor de audiência", os programas televisivos de entretenimento iniciaram uma briga para saber quem seria o campeão de audiência em determinados horários.

Sodré (2002), que estudou o grotesco em sua conceituação, história, tipos e formas de manifestação na litera- 
tura, no cinema e na televisão, propõe a seguinte definição do fenômeno: "grotesco é [...] a sensibilidade espontânea de uma forma de vida. É algo que ameaça continuamente qualquer representação (escrita, visual) ou comportamento marcado pela excessiva idealização. Pelo ridículo ou pela estranheza, pode fazer descer ao chão tudo aquilo que a idéia eleva alto demais" (2002, p. 39).

Nesse contexto, a piada tem o poder de tirar alguém ou algo do status de inatingível, pois a descontração permite um tipo de aproximação que o sério não permite. É possível fazer humor com qualquer tipo de assunto, com qualquer pessoa, com qualquer entidade. Quando alguém considerado importante pela sociedade é pego em alguma situação constrangedora, capaz de provocar riso, de imediato ele perde a pose de inalcançável, de diferente dos demais. Todos estão expostos a situações incontroláveis como um tropeço, uma queda, uma gagueira, uma dor de barriga, e essas situações estranhas ou ridículas fazem com que ninguém seja maior, ou melhor, do que ninguém.

Dentre os diversos subgêneros do grotesco propostos por Sodré (representado, atuado, espontâneo, escatológico, teratológico, chocante e crítico), este último é o que nos interessa mais de perto, dada a natureza do objeto estudado. Este subgênero se caracteriza por, mais que expor um fenômeno para a contemplação, permitir reflexões, discussões do objeto visado. Também costuma expor ao ridículo personalidades e/ ou entidades poderosas. Trata-se de um recurso para desmascarar convenções e ideais, ora rebaixando as entidades pretensiosas, ora expondo de modo tragicômico os mecanismos do poder abusivo.

\section{O CQC}

O programa Custe o Que Custar, mais conhecido pela sigla CQC, é originalmente Argentino ("Caiga Quien Cai$g a^{\prime \prime}$, que em uma tradução livre pode ser interpretado como "que caia quem tiver de cair"), onde está no ar há mais de dez anos. O formato adotado já foi exportado para diversos países e só em março de 2008 chegou ao Brasil, pela rede de televisão Band.

A proposta do programa, segundo está em seu site, é: "com humor inteligente, audacioso e muitas vezes ácido, fazer um resumo semanal das notícias". Seguindo a proposta do modelo original, busca confrontar e questionar as pessoas, sempre fazendo uso do humor, abordando os entrevistados com perguntas fora do padrão estabelecido para reportagens e entrevistas jornalísticas. A principal marca do CQC é a irreverência.

Para comandar o programa, o jornalista Marcelo Tas foi o nome escolhido. Não é de hoje que Tas aposta na mistura de jornalismo e humor. Nos anos 80, encarnou o personagem de um repórter denominado Ernesto Varela. Este personagem fazia matérias que desde então já aludiam ao estilo do programa CQC: indagava políticos sobre os problemas do país e suas condutas, sempre com um toque de humor. O "repórter" Varela teve a ousadia de perguntar para o então candidato à presidência da República, Paulo Maluf, se ele era mesmo "ladrão". Antônio Brasil, jornalista e professor de jornalismo da UERJ, em um artigo para o site Comunique-se, afirmou que "o ator Marcelo Tas e seu alter ego jornalista, o Ernesto Varela, faziam perguntas que nós jornalistas não tínhamos a coragem de fazer. Mas ele podia. Ernesto Varela não existia. Era um ator se passando por jornalista. Através do humor, Ernesto Varela era a voz da nossa consciência".

Despidos de qualquer personagem quando adentram ao Congresso Nacional, os repórteres, segundo o programa, querem mostrar que utilizam a ferramenta do humor como base, mas que não são palhaços e que não diferem de outros jornalistas que ali fazem reportagens. Danilo Gentili e Rafael Bastos questionam os parlamentares com perguntas diretas e críticas. Tais questionamentos não são vistos com bons olhos pelos políticos, o que resultou na expulsão e cancelamento da permissão de entrada no Congresso do programa $C Q C$, na condição de imprensa.

Analisaremos a seguir os programas referentes aos dias 7 e 14 de Abril e 23 de Junho de 2008 que foram ao ar com um quadro específico intitulado " $\mathrm{CQC}$ no Congresso". Foram mantidos, na medida do possível, os termos utilizados pelos personagens que fazem os programas, como forma de garantir o real entendimento do contexto.

\section{CQC no Congresso Nacional}

No programa que foi ao ar em 7 de abril de 2008, o repórter Danilo Gentili inicia sua matéria propondo o que ele chama de "tour" pelo Congresso, para que se entenda como funciona (e aí ele criticamente diz "se é que já funcionou um dia") o Congresso Nacional Brasileiro. Ao assim proceder, o repórter já busca desqualificar e expurgar a instituição. Ao adentrar o Salão Verde, Gentili chama a atenção para o fato de que o Congresso é o local onde se resolvem os problemas do país, porém nenhum dos parlamentares aparenta estar muito preocupado. Danilo sugere: "vamos entrar no clima e descansar um pouco". Segue então em busca de algum deputado que esteja trabalhando. Na primeira porta que bate, uma moça avisa que o deputado se encontra, mas "está ocupado". O programa usa grafismos digitais para inserir um nariz crescendo, fazendo uma referência ao personagem Pinóquio. Fazendo esse tipo de intervenção, o programa acaba por tirar a credibilidade dos entrevistados, pois suas respostas são entendidas como mentiras e, além disso, o entrevistado só saberá isso se assistir ao programa.

Após falar com a secretária, um "balão de pensamento" aparece no repórter como se ele estivesse imaginando o deputado ocupado fazendo suas necessidades fisiológicas. O telespectador pode simplesmente achar engraçado o fato de imaginar o deputado no banheiro, mas é pouco provável que perceba as segundas inten- 
ções por trás da piada. Essa metáfora dá a entender que o deputado não tem nenhum trabalho útil e que, se está ocupado, o único lugar onde poderia estar é no banheiro. Essa estratégia de dominação está dentro da estratégia tropo, que faz uso das figuras de linguagem, que são comuns no discurso cotidiano, para sustentar relações de dominação.

\section{A expulsão}

No programa de 14 de abril de 2008, Danilo Gentili retorna ao Congresso Nacional para mais uma reportagem. Ele abre a reportagem com o seguinte questionamento: "No começo de março o secretário do Ministério da Fazenda afirmou que: 'gente rica não paga imposto'. O CQC está aqui em Brasília e veio averiguar esse assunto de perto. Como estão votando a reforma tributária, o CQC quer saber: será que adianta reformar uma lei se os "figurões" não vão cumpri-la?". Sob a ótica de Bergson, que defende que o humor é um exercício em sociedade, se o telespectador não tem absolutamente nenhum conhecimento sobre tal reforma, dificilmente alguma piada terá graça para ele, pois estará totalmente fora do contexto.

Dando continuidade à matéria, o repórter entrevista $\mathrm{o}$ deputado Marcelo Teixeira, indagando-o sobre qual seria o seu principal projeto na câmara. Enquanto o deputado fala, as palavras ditas por ele "aparecem" sendo colocadas dentro de um liquidificador. Ao final da explanação, as palavras são "batidas" no liquidificador e surge um ponto de interrogação, numa alusão de que tudo o que o deputado fala não fez sentido algum e que ele não respondeu à pergunta que lhe foi dirigida. Mais uma vez os elementos gráficos introduzidos na matéria é que produzem a piada, pois o repórter não diz nada além de um agradecimento ao deputado. Além disso, a resposta do deputado parece ter sido feita de uma forma automática, já que não foi direta à pergunta do repórter, foi vaga. Essa automatização é um dos pontos em que Bergson mais se apega ao falar sobre o humor. Quando se esperava de um deputado que ele tivesse uma maleabilidade para responder a algum repórter, ele apresenta frases feitas que para ele, pelo visto, deviam responder a qualquer questionamento relacionado a seu cargo e a seu trabalho.

Em seguida, surgem imagens de uma câmera, provavelmente escondida, mostrando um senhor avisando que o programa não mais poderia fazer reportagens dentro da Câmara. O repórter, após a saída dos seguranças, volta-se para o telespectador dizendo: "O CQC acaba de ser proibido de fazer mais matérias aqui na Câmara dos Deputados. Pelo jeito, os políticos só querem responder às perguntas que lhes são convenientes. Não é uma ditadura, mas a censura tá aí".

O programa tenta ainda gravar algumas cenas no gramado em frente ao Congresso. Discretamente, com uma câmera escondida, o cinegrafista filma um dos seguranças do Congresso Nacional argumentando com o repórter sobre os locais onde ele poderia filmar. Durante a cena, o segurança pronuncia a palavra "inclusive" como "incrusive" e esse erro gramatical é ressaltado, sendo elevado à condição de piada. De acordo com a teoria da superioridade, o riso provocado por erros gramaticais alheios se faz como conseqüência do sentimento de uma inteligência superior à do personagem que erra. Essa valorização do erro também pode ser caracterizada como um "expurgo do outro". Essa estratégia de dominação dentro da matéria mostra os parlamentares e seus seguranças como inimigos dos repórteres e, consequentemente, dos telespectadores que desejam assistir às matérias feitas naquele ambiente.

Apesar da liberdade de expressão ser um direito adquirido de cada cidadão e coibir esse direito possa ser caracterizado como censura, ao telespectador não fica a possibilidade de analisar o acontecido pelo lado do Congresso e de seus representantes. O programa era novo e, ao adentrarem o Congresso com o cadastro de imprensa, não era esperado o advento do humor como característica nas perguntas feitas aos deputados. Ainda que a proibição e expulsão não seja a melhor maneira de agir já que vivemos em uma democracia representativa, exibir os representantes do Congresso Nacional e seus seguranças como inimigos da democracia faz com que o programa transpareça uma tentativa de manipulação do público para que ele se comova com sua causa e os apóie.

\section{A campanha "CQC no Congresso"}

Diante da proibição, o programa realizou uma campanha intitulada "CQC no Congresso", que objetivava angariar o apoio da população. A campanha dispunha de uma página na internet (http:// www.cqcnocongresso.com.br) na qual o público simpatizante podia assinar o seu voto de apoio à causa. Nas demais matérias dos nove programas subseqüentes, os repórteres indagavam entrevistados dos mais diferentes segmentos sociais sobre a proibição e pediam suas opiniões.

A matéria inicial apresenta representantes de todos os lados que compõem essa discussão. Jornalistas, humoristas e políticos, aparecem apoiando o CQC e questionando a decisão de impedi-los de entrar no Congresso. Os nomes provavelmente não foram escolhidos aleatoriamente, pois os representates dos segmentos citados são, em sua maioria, referência no assunto e com imagem e nome respeitados. Um deles é Angeli, cartunista que usou o humor para criticar a censura durante a ditadura brasileira. Ao repórter, ele diz que "a ditadura, por exemplo, demorou muito tempo para entender o humor. Agora eu acho que está um escárnio tão grande que eles entendem e não estão nem aí".

O jornalista Boris Casoy também dá a sua opinião em relação ao humor junto ao jornalismo. "Essa irreverência do humorismo muitas vezes traz em seu bojo uma exigência de transparência. Quem está proibindo está 
com medo de alguma coisa. Está com medo dessa transparência que esse humor ardido, esse humor agudo, provoca". O jornalista chama atenção para a diferença da abordagem que o humor permite, principalmente sendo ela aliada a uma abordagem jornalística. A utilização da figura de Boris Casoy também dá credibilidade ao que está sendo dito, pela imagem que o jornalista possui e carrega há muitos anos como profissional.

Um representante da Câmara, o deputado federal Ciro Gomes, também manifesta seu apoio ao programa quando diz que "nenhuma restrição no Congresso cabe. Vocês são chatos pra caramba, mas têm talento". Chamando os integrantes do programa de "chatos", o deputado demonstra que nem sempre é agradável responder às perguntas dos repórteres, mas que não é por isso que se deve proibi-los de entrar no Congresso, visto que o talento que o deputado observou neles, na sua opinião não deve ser tolhido com a incoerente restrição de sua entrada na intitulada "casa do povo". Buscando um representante do meio político, o programa tenta mostrar que buscou ouvir todos os lados que envolvem a situação.

Nesta matéria, também é exibido o trecho de uma reportagem do personagem Ernesto Varela. Nela, em 1984, Varela questiona Nelson Marchezan, deputado federal: "segundo diz a imprensa, os políticos estão perdendo a credibilidade. $O$ que o senhor acha dessa afirmação?". O deputado então responde: "eu reconheço que nós temos muitos problemas e também temos muitos erros, mas é verdade também que nós representamos a sociedade brasileira com todas as suas virtudes e seus defeitos".

Por outro lado, toda essa comoção pública provocada pelo CQC permite o entendimento de que se possa estar fazendo uso do humor como forma de dominação, como as que foram discutidas no segundo capítulo. O programa usa da narrativização quando conta toda uma história em torno da questão do impedimento de acesso ao Congresso.

Quando tenta ainda passar a idéia de que a permissão do programa para adentrar ao Congresso é um desejo universal, usa da universalização, transparecendo que inúmeras pessoas formadoras de opinião estão apoiando a campanha e que elas são porta-vozes de um desejo coletivo. $\mathrm{O}$ site na internet pode ser reconhecido como um processo de unificação, por reunir assinaturas de quaisquer lugares do mundo em prol de um desejo comum.

É possível perceber, com isso, que o discurso do humor do programa é um grotesco crítico, que desmascara convenções e ideais, ora rebaixando as entidades pretensiosas, ora expondo de modo tragicômico os mecanismos do poder abusivo. O programa pode defender isto como uma maneira de expor as verdades sobre algumas questões, mas esta estratégia também é manipuladora do público telespectador.

Dessa forma, o humor pode ser tão perverso quanto o discurso que proíbe sem possibilidade de argumentação. O humor rebaixa pessoas e entidades e retira delas qualquer tipo de credibilidade, pois elas se tornam objetos de escárnio e riso, fazendo com que aqueles indivíduos não sejam mais respeitados. É possível pensar também em como o humor, nesses casos e em outros, se assemelha à política do "pão e circo", pois oferece diversão em cima de questões sérias, fazendo com que uma sociedade já não mais as questione e sim, somente ache graça. Ainda que este tipo de grotesco possa remeter a alguma reflexão por conta de seus telespectadores, isso só acontece em uma pequena parcela que se proponha a assistir a ele de maneira criteriosa, o que não é o caso de grande parte da população.

\section{Considerações finais}

O processo de construção do presente artigo permitiu compreender as diferentes formas de conceituar o humor, tomando como referencial teórico o pensamento de Bergson (2001), Propp (1992) e Freud (1996) bem como relacioná-los à comunicação e ao entretenimento. $\mathrm{O}$ tipo de humor que se exerce nos meios de comunicação de massa ou a forma como se reage frente a situações humorísticas mostra a maneira como as pessoas se comportam diante do mundo. O humor, sendo uma forma de expressão, também carrega consigo uma capacidade de manipular o público.

Também foi notado que o humor nunca é desproposital. Ao rir, as pessoas abrem suas defesas, permitindo uma dominação. E isto é usado constantemente em diferentes tipos de programas humorísticos. Além do que, ficou notório que o humor faz parte do espetáculo no qual se tornou a sociedade atual onde aparecer se tornou o objetivo maior de vida de pessoas e empresas.

Tendo como objeto de estudo o programa CQC, o presente trabalho procurou atrelar, através desta pesquisa, o humor ao jornalismo. A leitura e análise das edições do programa possibilitaram que se contextualizassem as diferentes tipificações do humor, da ideologia, da dominação, da sociedade do espetáculo e do grotesco. $\mathrm{O}$ programa CQC busca discutir os mais diferentes assuntos do país pela visão do humor. Não se trata de novidade, mas o programa conseguiu gerar uma discussão em torno de censura, do que seja o humor, do jornalismo e da situação política do país sem deixar de ser um programa de entretenimento. Conseguiu um feito e uma comoção nacional que poucos programas que já estão na grade da televisão brasileira há muito mais tempo não conseguiram.

Da mesma forma que o humor pode ser uma porta para uma abordagem diferenciada e para perguntas sem rodeios, dentro deste poder que a televisão detém, satirizar os representantes de seu país pode fazer com que as pessoas que assistam aos programas não mais os respeitem e não acreditem em uma melhoria no sistema político da nação. Ainda que exista a corrupção, provocar o 
desrespeito pode não ser a melhor forma de fazer com que as pessoas lutem por seus direitos.

O humor dentro do jornalismo pode ainda atrair a atenção de um público que, normalmente, não se interessa em assistir a jornais tradicionais nem em discutir assuntos como a política. É válido atrair o público jovem a discutir estes assuntos, mas a forma como o tema é abordado pode, em vez de criar neles uma consciência política, gerar um sentimento ainda maior de que não exista mais jeito, e que portanto devemos nos dedicar apenas ao riso puro.

Tendo consciência de que o humor não é inocente, pode-se perceber dentro do $C Q C$ várias estratégias de manipulação do público. Como visto no capítulo de análise, o programa usa figuras importantes para agregar valor a sua causa, entrevistando-as em relação à proibição de entrar no Congresso e utilizando suas palavras de apoio para valorizar a campanha. Gera também uma comoção nacional em torno da proibição, já atribuindo a ela o valor de censura, algo abominado em tempos de democracia.

Em prol dessa causa, o programa buscou unificar os telespectadores. Passando uma imagem de incompreendidos, defendem-se afirmando que estavam exercendo somente a liberdade de imprensa, permitida e valorizada nos dias atuais. Usando o riso como uma forma de "abrir portas", fazem dele instrumento para gerar a discussão e para permitir uma dominação. Os responsáveis pela proibição são expostos como inimigos do povo e da democracia.

Quanto ao questionamento sobre se é válido fazer jornalismo dessa maneira, como todas as situações da vida, esta possui dois lados. Por um lado, o jornalismo com humor possibilita chamar a atenção de outros públicos para assuntos que, quando expostos em um jornalismo tradicional, não são tão atraentes. Além disso, o humor permite aos repórteres diferentes abordagens aos seus entrevistados e aos temas. Com o humor, o jornalista pode fazer questionamentos de uma maneira que no tradicional soaria antiético, mas, dentro do humor, é engraçado e sagaz.

Por outro lado, é necessário perceber também se é válido levantar certas questões sobre a ótica do humor. Se com o humor é possível levar certos assuntos à consciência de outro público, será que não estaria levando, na realidade, a uma pseudo-consciência, já que tudo é tratado com escárnio e as pessoas já são expostas como inimigas? Será que é válido gerar uma discussão enfraquecendo um dos lados?

Estas perguntas devem ser questionadas e discutidas, mas não necessariamente respondidas, pois, na verdade a comunicação com humor é um paradoxo. A potência do paradoxo não é seguir a outra direção, mas mostrar que o sentido toma sempre as duas direções ao mesmo tempo, que não é interessante separar duas tendências, uma apropriada ao pensamento dito sério e outra destinada ao lúdico, recreativo e humorístico. Todo sentido é, por, um duplo sentido. Toda verdade deve, portanto, ser dotada de boa dose de humor mamecos

\section{REFERÊNCIAS}

ACSELRAD, Márcio. O humor como estratégia de comunicação. Disponível em: <http:/ / www.compos.org.br/ data/biblioteca_112.PDF>. Acesso em 31 set. 2008.

BAND. Programa Custe o Que Custar. Disponível em: <http://www.band.com.br/cqc/>. Acessos diversos

BERGSON, Henri. O riso. Tradução Ivone Castilho Benedetti. São Paulo: Martins Fontes, 2001.

DEBORD, Guy. A sociedade do espetáculo: comentários sobre a sociedade do espetáculo. Tradução Estela dos Santos Abreu. Rio de Janeiro: Contraponto, 1997.

ENCARTA, Enciclopédia Microsoft. Teoria do humor. Disponível em: <http://encarta.msn.com/artcenter_0.7/Social_Science.html\#tcsel>. Acesso em: 12 out. 2008.

FREUD, Sigmund. Obras psicológicas completas de Sigmund Freud: edição standard brasileira. Tradução Jayme Salomão. Rio de Janeiro: Imago, 1996.

JAPPE, Anselm. A arte de desmascarar. Disponível em: <http://www.geocities.com/grupokrisis2003/ ajpp.htm>. Acesso em: 16 nov. 2008.

PROPP, Vladimir. Comicidade e riso. São Paulo: Ática, 1992.

SODRÉ, Muniz. O império do grotesco. Rio de Janeiro: Mauad, 2002.

THOMPSON, John B. Ideolodia e cultura moderna: teoria social crítica na era dos meios de comunicação de massa. 3. Ed. Petrópolis, RJ: Vozes, 1995. 